\title{
Comparative Study between D2EHPA and Cyanex 272 as Extractants of Mn(II) from a Leached Liquor Produced by Reductive Leaching of a Pyrolusite Ore with $\mathrm{SO}_{2}$
}

\author{
Roberto Pérez-Garibay, Javier Martínez-Jiménez, \\ Alejandro Uribe-Salas, Antonia Martínez-Luévanos \\ Centro de Investigación y de Estudios Avanzados del IPN, Ramos Arizpe, México \\ Email: roberto.perez@cinvestav.edu.mx
}

Received June 29, 2012; revised July 27, 2012; accepted August 9, 2012

\begin{abstract}
This paper compares the efficiency of D2EHPA and Cyanex 272 to extract the divalent manganese cation from an actual leaching solution obtained by reductive leaching of a low-grade pyrolusite ore, using $\mathrm{SO}_{2}$ gas. The studied variables were the extractant concentration in the organic phase, the $\mathrm{pH}$ of the leached liquor and the volume ratio between organic phase and leached liquor. It was observed that D2EHPA is a better extractant than Cyanex 272. Therefore, with the best experimental conditions found, both extractants reach a manganese recovery around $95 \%$ with five extraction stages conducted under the following conditions: $25^{\circ} \mathrm{C}, \mathrm{O} / \mathrm{A}=2,10 \%$ volume of extractant concentration in the organic phase, $\mathrm{pH}$ of the leached liquor before the mixing between 8 and 8.5, and one minute of mixing time for each extraction stage.
\end{abstract}

Keywords: Manganese Solvent Extraction; Manganese Leaching; Manganese; Pyrolusite

\section{Introduction}

In last decades the manganese demand has increased mainly due to the growth of the steelmaking industry. The most important manganese minerals are pyrolusite $\left(\mathrm{MnO}_{2}\right)$, rhodochrosite $\left(\mathrm{MnCO}_{3}\right)$, rhodonite $\left(\mathrm{MnSiO}_{3}\right)$, black manganite $(\mathrm{MnO}(\mathrm{OH}))$, and alabandite $(\mathrm{MnS})$ [1] .

According to Zhang et al. [2], after the steelmaking application of manganese, the aluminum industry shows an increasing demand of manganese. A third place in manganese consumption is occupied by the electronic industry, which consumes both electrolytic and chemical grade manganese dioxide (EMD and CMD) in the fabrication of disposable and rechargeable batteries. Currently, the growing market of mobile communications has increased significantly the demand of batteries and consequently of EMD. Notably, the batteries industry demands a concentrate of manganese ore containing above $80 \%$ of $\mathrm{MnO}_{2}$ with a total iron oxides content below $1 \%$.

Generally, low grade manganese minerals are processed by hydrometallurgical techniques. There are several methods to extract the metal from the leaching solution, such as ionic exchange, solvent extraction with electrowinning and precipitation. However, the solvent extraction with electrowinning is the most appropriate method to obtain a product of higher value.

The elimination of manganese impurities of nickel and zinc from leach liquors of cobalt is the most common objective of manganese extraction studies [3-7]. However, there are few studies on the solvent extraction method to concentrate a manganese leached solution out of a pregnant solution obtained by $\mathrm{SO}_{2}$ leaching of lowgrade pyrolusite ores. The scope of this work was to study the effect of $\mathrm{pH}$ of the leached solution, type of extractant and its concentration in the organic phase, number of extraction stages and the ratio between the organic and leached liquor, on the manganese recovery.

\section{Review of Previous Work}

This section presents a brief review of previous studies that used di-(2-ethylhexyl) phosphoric acid (D2EHPA) and bis(2,4,4-trimethylpentyl) phosphinic acid (Cyanex 272), to extract metals of the same group of manganese. One of the first research works on solvent extraction of manganese is that of Yoshida et al. [8], who studied the use of thenoyltrifluoracetone as extractant. Their objectives were focused to determine the formula of the manganese-extractant complex and the distribution ratios. To separate manganese from cobalt of a sulfated solution, Hoh et al. [9] carried out an experimental work with D2EHPA, observing that a high degree of separation is obtained when the $\mathrm{pH}$ of the solution is $4.2, \mathrm{O} / \mathrm{A}=2$ for solvent extraction and they claimed that four extraction 
stages were sufficient for a good separation.

Sato and Nakamura [10] found out that the distribution coefficient is dependent on the concentration of the acid and D2EHPA, suggesting that the extraction is carried out through a cation-exchange mechanism.

Hughes and Biswas [11] used a rotating diffusion technique to extract the manganese of an aqueous solution containing $<0.5 \mathrm{~mol} / \mathrm{L} \mathrm{Mn}$ (II) $(\mathrm{pH}$ between 2.70 and 3.57 ), with an organic solution whose D2EHPA concentration in $\mathrm{n}$-hexane as solvent was $<1.13 \mathrm{~mol} / \mathrm{L}$. They observed the formation of a complex in the aqueous film, close to the organic-aqueous interface, which was identified to be the rate-limiting step.

A series of shake-out tests was undertaken by Cheng [12] to investigate the fundamentals of the separation of manganese from cobalt and nickel using D2EHPA in kerosene. The author concluded that the separation of manganese from cobalt and nickel by D2EHPA in kerosene was affected by temperature and $\mathrm{pH}$. At $\mathrm{pH} 3.0$, better separation of manganese from cobalt and nickel was achieved at room temperature $23^{\circ} \mathrm{C}$. Meanwhile at $\mathrm{pH} 3.5$, better separation of manganese from cobalt was achieved.

Cheng et al. [13] had also used solvent extraction to recover the manganese from solutions also containing nickel, cobalt and magnesium, concluding that D2EHPA is a convenient reagent for selective manganese extraction. As well, Pagnanellia [14] studied the use of D2EHPA as extractant and n-heptane as a diluent, analyzing the effect of the extractant concentration in the range from 0.05 to $2.5 \mathrm{M}$, upon the separation of manganese of both a synthetic and an actual solution employing a volume ratio $1: 1$ of the organic and aqueous phases.

Zhang and Cheng [15] enounced that solvent extraction plays a vital role in purification and separation processes and that D2EHPA is the cheaper and more widely used organic to extract the manganese when it is present as impurity in a leaching solution. Sousa Junior et al. [16] studied the extraction of manganese sulfate of the $\mathrm{MnSO}_{4}$ $\mathrm{H}_{2} \mathrm{SO}_{4}-\mathrm{H}_{2} \mathrm{O}-\mathrm{D} 2 \mathrm{EHPA}$-isoparaffin system making use of a thermodynamic model based on balance equations of mass and charge. They also found that the equilibrium constant of the extraction was $5.18 \times 10^{-4}$. Also, they observed that under the experimental conditions used, one mole of hydrogen ion was released for one mole of metal extracted and that the separation factor was $\mathrm{pH}$ dependent. In an ongoing study, Devi et al. [17] used this regent employing kerosene as solvent to separate manganese and cobalt from sulfated solutions. The authors compared three extractants and concluded that the selectivity order for manganese separation was D2EHPA, PC88 and Cyanex 272. On their part, Salgado et al. [18] studied a hydrometallurgical route based on the liquid-liquid extraction technique using Cyanex 272, for the selective separation of metal values, in particular, zinc and manganese, from spent alkaline batteries. They observed that zinc and manganese are easily separated $(\mathrm{pH} \approx 2.0)$ using $20 \%(\mathrm{v} / \mathrm{v})$ Cyanex 272 dissolved in Escaid 110 at $50^{\circ} \mathrm{C}$.

The single-stage extraction of manganese(II) sulfate with Cyanex 302 in kerosene $(\mathrm{O} / \mathrm{A}=1)$ was also studied by Devi and Mishra [19]. They established the mechanism of extraction and stoichiometries of metal-containing extracted species. They also observed that the temperature variation studies showed that the extraction process is exothermic, which was confirmed by the negative value of $\Delta \mathrm{H}$.

It is interesting to observe that most of the research work of solvent extraction of manganese was conducted making use of synthetic solutions where the metal is present as impurity. On the contrary, the interest of this work is to compare the performance of D2EHPA and Cyanex 72 reagents in kerosene, to extract $\mathrm{Mn}$ (II) out of an actual leached solution. Manganese pregnant liquor was obtained by leaching of a low-grade pyrolusite ore using $\mathrm{SO}_{2}$ as the reductive reagent; the manganese concentration in this liquor was approximately $0.085 \mathrm{M}$. Thus, the aim of this study is to share the guidelines and the most appropriate operating conditions to obtain an efficient solvent extraction process.

\section{Experimental Part}

The elemental analysis of the ore was conducted using X-ray fluorescence (\%, w/w): Mn (18.80), Fe (12.81), Si (23.83), Al (1.18), Ba (1.11), Ca (0.59) and $\mathrm{O}$ (42). Based on this analysis and on the stoichiometry of the oxidised species, a mineralogical composition was estimated (\%, w/w): $\mathrm{MnO}_{2}$ (28.78), $\mathrm{Fe}_{2} \mathrm{O}_{3}$ (17.72), $\mathrm{SiO}_{2}$ (49.33), $\mathrm{Al}_{2} \mathrm{O}_{3}$ (2.15), $\mathrm{BaO}$ (1.19) and $\mathrm{CaO}(0.79)$. Notably, these results are in qualitative agreement with the results obtained using X-ray diffraction.

The ore was finely ground to reach a particle size distribution $-38 \mu \mathrm{m}$. The manganese dissolution was conducted by reductive leaching of the low-grade pyrolusite ore using $\mathrm{SO}_{2}$ as the reductant. The leaching was carried out in a two-litre glass cylindrical reactor operated in batch mode. The reactor was properly instrumented to measure and control the temperature, $\mathrm{pH}$, mixing rate and gas flow bubbled into the reactor. Figure 1 schematically illustrates the experimental setup. During the leaching of $50 \mathrm{~g}$ of ore, the experimental conditions were $60^{\circ} \mathrm{C}$ for 120 minutes, mixing to $800 \mathrm{rpm}, 1600 \mathrm{~mL}$ of pulp and $0.096 \mathrm{~mL} / \mathrm{s}$ of $\mathrm{SO}_{2}$ gas. After the leaching, the liquor was separated from the solids by filtration.

The leach liquor contained $90 \%$ of $\mathrm{Mn}$ and $0.17 \%$ of the Fe originally contained in the ore. The poor Fe dissolution was caused by the fact that practically all the Fe was occluded into quartz particles. Thus, the manganese concentration in this liquor was around $0.085 \mathrm{M}$. 

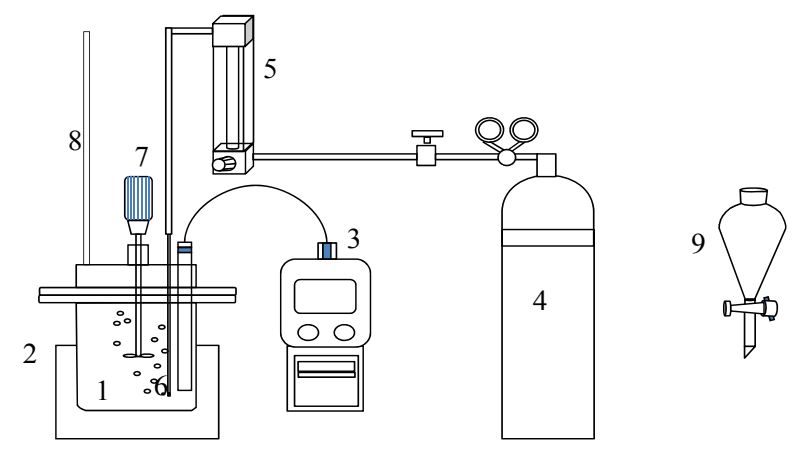

Figure 1. Experimental set-up: 1. Reactor; 2. Heating mantle; 3. pH meter; 4. $\mathrm{SO}_{2}$ Gas; 5 . $\mathrm{SO}_{2}$ flow meter; 6. Gas diffuser; 7. Mixer; 8. Gas exit; 9. Separation funnel.

In the solvent extraction stage, the extractants were dissolved in kerosene in order to have the following extractant concentrations: $5 \%, 10 \%, 15 \%, 20 \%$ and $25 \%$ by volume. Considering that the affinity of the extractants for the metal ions is as follow: $\mathrm{Fe}^{2+, 3+}>\mathrm{Zn}^{2+}>\mathrm{Cu}^{2+}>$ $\mathrm{Co}^{2+}>\mathrm{Ni}^{2+}>\mathrm{Mn}^{2+}>\mathrm{Mg}^{2+}>\mathrm{Ca}^{2+}$, it was necessary to eliminate the $\mathrm{Fe}$ impurities of the leaching solution prior to the extracting stage. To precipitate the impurities of $\mathrm{Fe}$, the $\mathrm{pH}$ was increased to 7.5 with $\mathrm{NH}_{4} \mathrm{OH} 5 \mathrm{M}$. Initially, the leaching solution contained $4932 \mathrm{ppm}$ of $\mathrm{Mn}$ and 639 ppm of $\mathrm{Fe}$, whereas after the precipitation of $\mathrm{Fe}(\mathrm{OH})_{2}$, the iron content dropped to about $0.03 \mathrm{ppm}$, with only a small fraction of $\mathrm{Mn}(\mathrm{II})$ being precipitated as a collateral effect (5.7\%).

The mixing of the two phases and solvent extraction separation was carried out in a separation funnel of 125 $\mathrm{mL}$. Each test consists of five separation stages with $60 \mathrm{~s}$ of manual agitation, being careful to apply similar agitation intensity in each test. After each extraction stage, the mixture was let to stand still during 20 minutes, permitting the complete separation of the phases. After that, a sample of the solution was withdrawn to measure the manganese concentration by atomic absorption. Before and after each extraction stage the $\mathrm{pH}$ of the aqueous phase was measured and eventually adjusted with a $\mathrm{NH}_{4} \mathrm{OH} 1 \mathrm{M}$ solution.

The initial tests were focused to evaluate the effect of the extraction time (mixing of phases), that is, the kinetics of the extraction. Once the kinetics and the optimal $\mathrm{pH}$ were known, the next stage was to determine the best organic/aqueous phase ratio. The effect of the extractant concentration in the organic phase was also studied, testing the following compositions: $5 \%, 10 \%, 15 \%, 20 \%$ and $25 \%$ by volume. Each test was conducted by duplicate and varying a parameter at the time, while keeping the others constant.

\section{Results}

\subsection{Determination of the Extraction Time}

Figure 2 shows the kinetics of manganese extraction

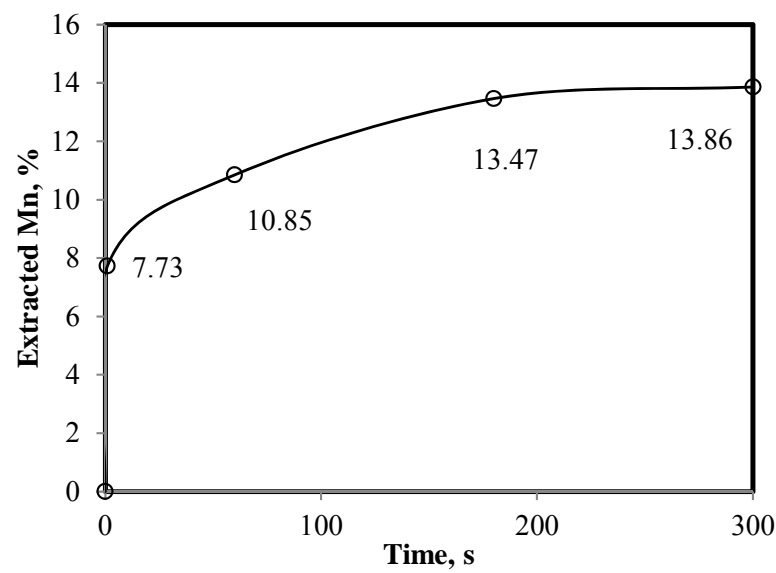

Figure 2. Kinetics of manganese extraction using D2EHPA as extractant. $\mathrm{pH}_{\text {initial }}=7-8, \mathrm{O} / \mathrm{A}=1 \%, 10 \%$ of extractant in organic phase, $25^{\circ} \mathrm{C}$, one mixing stage.

achieved in one mixing stage with D2EHPA, using a ratio of organic to leached liquor $(\mathrm{O} / \mathrm{A})$ of 1 , and $10 \%$ of extractant in kerosene. The results indicate that after three minutes, $13.47 \%$ of the manganese is recovered (i.e., extracted). A significant change of $\mathrm{pH}$ of the leached liquor was observed, which suggests that the reaction is controlled by the activity of the $\mathrm{H}^{+}$ion in the leached liquor, as it is discussed in the next section.

\subsection{Effect of the Initial $\mathrm{pH}$ of the Leached Liquor $\left(\mathrm{pH}_{\text {initial }}\right)$}

Figure 3 illustrates the effect of the $\mathrm{pH}$ of the leached liquor before the extraction, on the manganese recovery. The results show that above $\mathrm{pH}=8$, the Mn recovery rises exponentially. However, with both extractants, the organic-leached liquor dispersion is unstable above $\mathrm{pH}=$ 8.5 and therefore, it is necessary to operate from $\mathrm{pH} 8$ to 8.5. Apparently, this instability is because, according to Pourbaix diagrams, above $\mathrm{pH} 8.5$ manganese ions may precipitate has hydroxide. Notably, from this figure it is observed that in the range of $\mathrm{pH}$ between 5 and 8 , the manganese extraction with D2EHPA is about seven times more efficient than Cyanex 272.

Figure 4 compares the $\mathrm{pH}$ of the leach liquor before and after the mixing stage with the organic, this last is the $\mathrm{pH}$ at the equilibrium. Note that in the case of D2EHPA, the change of $\mathrm{pH}$ is larger than that of the Cyanex 272 and this behavior may be the reason of the higher extraction potential of D2EHPA and its larger distribution coefficients. This gradient of $\mathrm{pH}$ is caused by the release of hydrogen ions by the extractant which are exchanged by the metal cations to form an organometallic compound, thus causing the leach liquor to become acidified. This transference of $\mathrm{H}^{+}$from the organic to the aqueous phase decreases when the $\mathrm{pH}$ of the solution approaches the unity, reducing the extraction efficiency. 


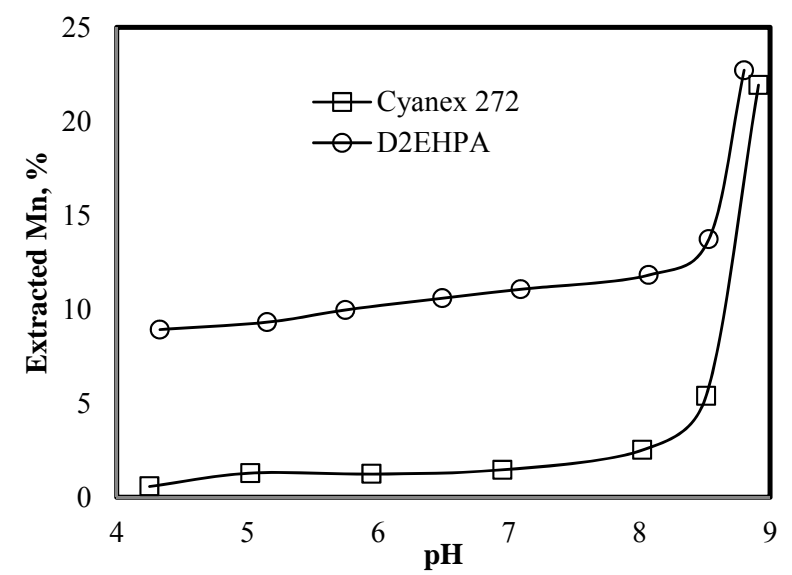

Figure 3. Effect of the pH on Mn extraction using Cyanex 272 and D2EHPA. $25^{\circ} \mathrm{C}, 10 \%$ extractant in the organic phase, $\mathrm{O} / \mathrm{A}=2$ and 1 minute of mixing time.

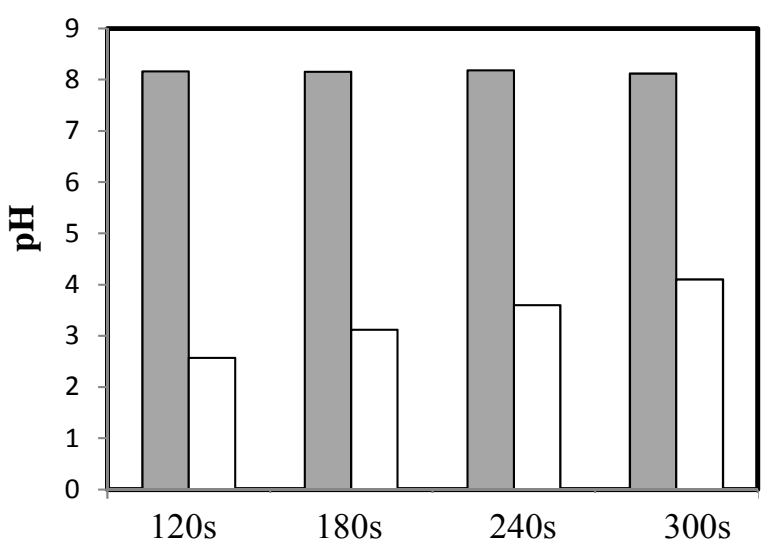

(a)

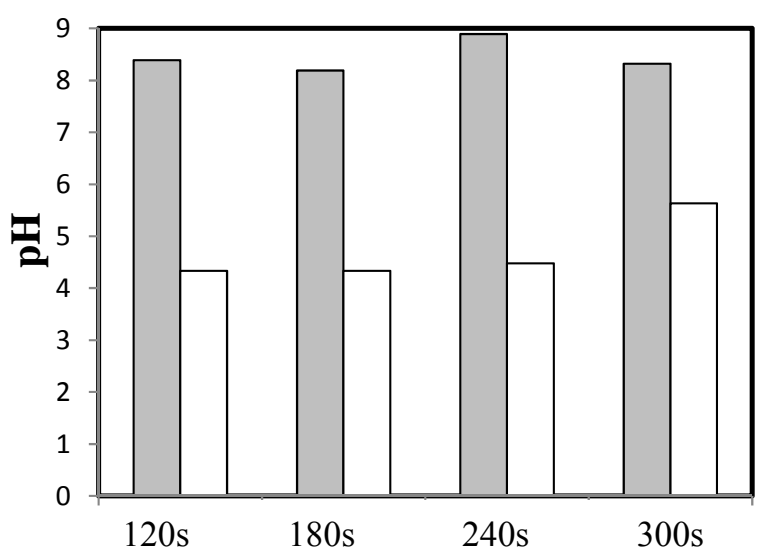

(b)

Figure 4. Gradient of pH before and after each extraction stage. (a) D2EHPA, (b) Cyanex 272. O/A = 0.5, 10\% of extractant in the organic phase. Gray bars: $\mathrm{pH}$ before extraction; White bars: pH after extraction.

\subsection{Effect of the Organic/Leached Liquor (O/A) Ratio}

Figure 5 shows the effect of the organic/leached liquor

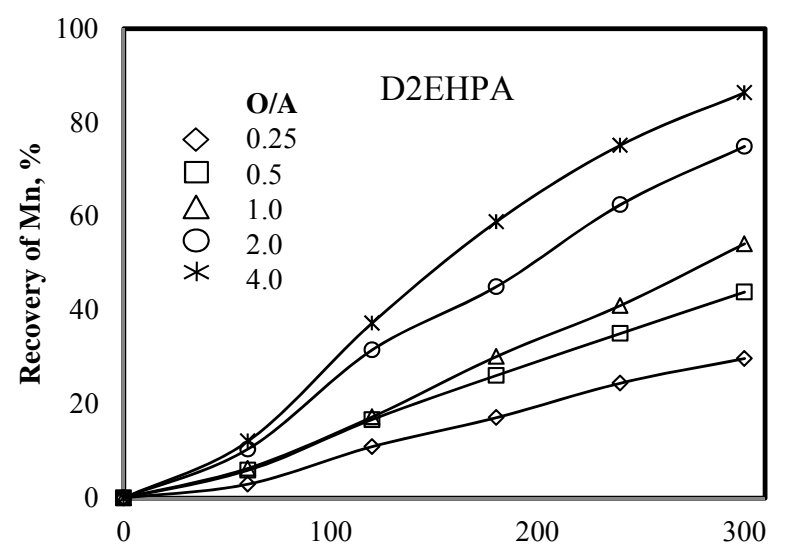

(a)

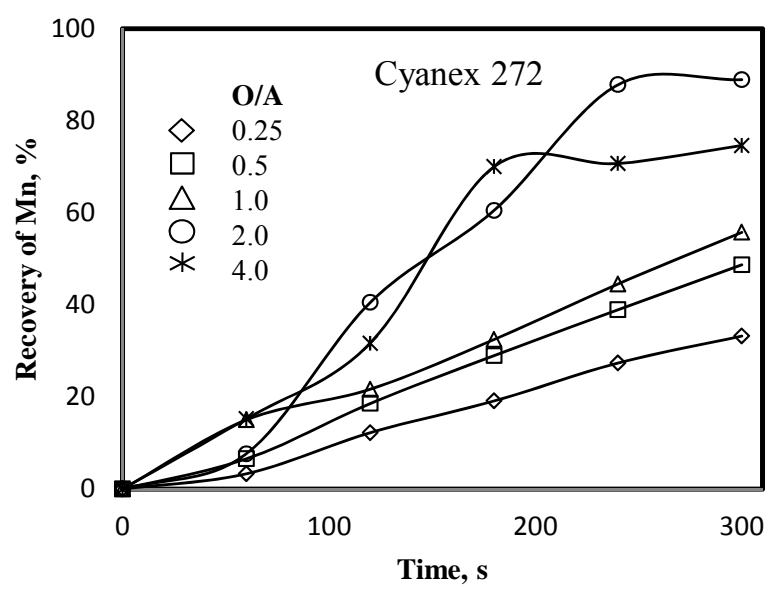

(b)

Figure 5. Effect of the organic/leached liquor (O/A) ratio, on manganese recovery using different extractants ((a) D2EHPA and (b) Cyanex 272). $\mathrm{pH}=7-8,25^{\circ} \mathrm{C}, 10 \%$ of extractant in the organic phase, five extraction stages and 1 minute of mixing each stage.

ratio on the kinetics of the extraction. Results indicate that the Mn recovery increases with the increase of the $\mathrm{O} / \mathrm{A}$ ratio and the time of reaction, with an organic phase composed by $10 \%$ of extractant and $90 \%$ of kerosene. Evidently, when the organic phase is more concentrated in extractant, the extractant molecules have more probabilities of reacting with the $\mathrm{Mn}(\mathrm{II})$, increasing its recovery. In both cases, with D2EHPA and Cyanex 272, the $\mathrm{pH}$ of the leached liquor was adjusted at a $\mathrm{pH}$ value between 8 and 8.5. Note that contrary to the results obtained with D2EHPA, the results obtained with Cyanex 272 show a more irregular behavior, which is due to difficulties in regulating the $\mathrm{pH}$ of the leached liquor.

\subsection{Effect of the Extractant Concentration in the Organic Phase}

With respect to the effect of the extractant concentration in the solvent, the manganese recovery increases as the 
extractant concentration is increased, as shown in Figure 6 ((a) for D2EHPA and (b) for Cyanex 272). It is evident that to extract more manganese it is necessary to have enough extractant, otherwise the absence of one of the reagents that participate in the reaction limits the extent of it. However, a high extractant concentration increases the viscosity and decreases the fluidity of the organic phase, reducing the mass transfer rate during the extraction. To avoid these problems, it is necessary to optimize the extractant concentration, without affecting the extraction extent.

\subsection{Distribution Coefficients}

A common way to evaluate the efficiency in solvent extraction separation is by means of the distribution coefficient (D), which is defined as the ratio of the concentration of the extracted metal in the organic and the concentration in the aqueous phase, in equilibrium with the

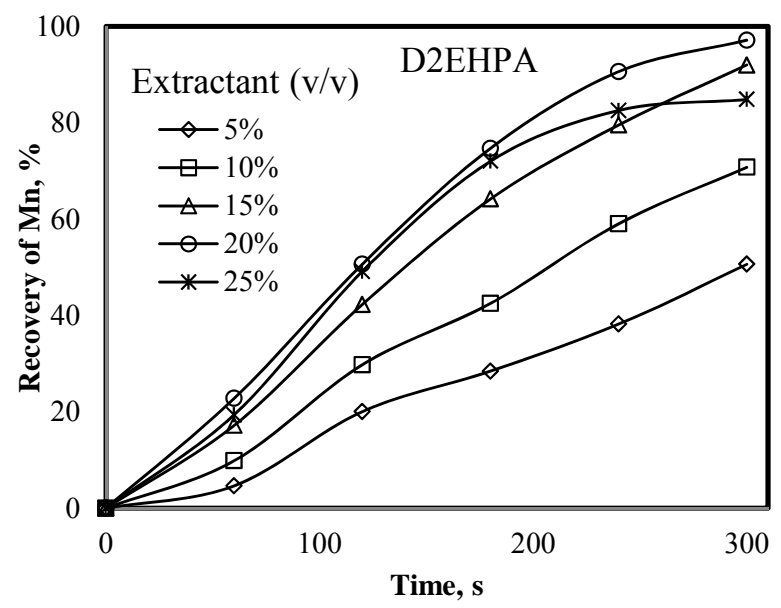

(a)

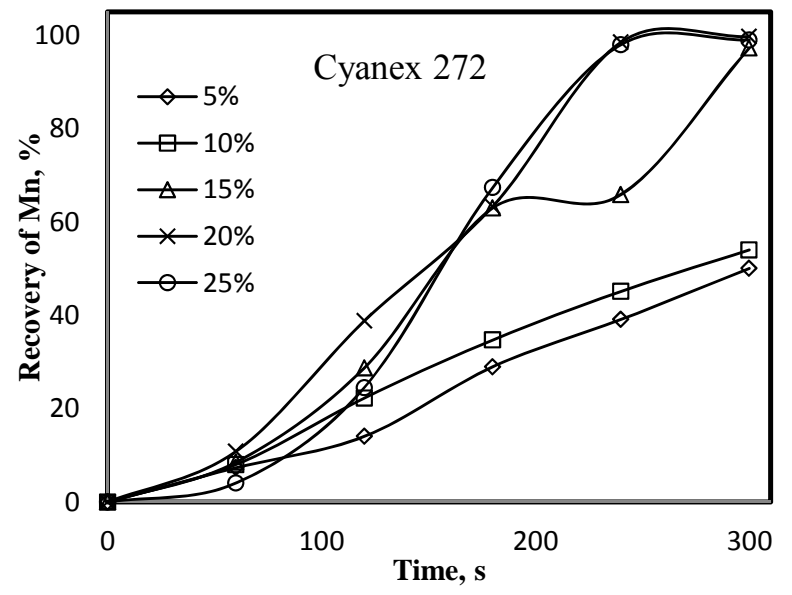

(b)

Figure 6. Effect of the extractant concentration on the manganese recovery. $\mathrm{pH}=8-8.5,25^{\circ} \mathrm{C}, \mathrm{O} / \mathrm{A}=2$, five extraction stages and $1 \mathrm{~min}$ of mixing each stage. (a) D2EHPA and (b) Cyanex 272. organic. Figure 7 compares the distribution coefficients of both extractants, showing that D2EHPA values are larger than those of Cyanex 272. These results reveal the superiority of D2EHPA as manganese extractant over Cyanex 272.

\section{Conclusions}

D2EHPA is more efficient than Cyanex 272 to extract the $\mathrm{Mn}$ (II) from a leach liquor obtained from the reductive leaching of a pyrolusite ore with $\mathrm{SO}_{2}$. Notably, it is sufficient two or three minutes of intimate contact between organic and aqueous phases to obtain the $100 \%$ extraction, i.e., to complete each extraction stage.

Manganese recovery increases as the extractant concentration in kerosene solvent increases. It is demonstrated that using D2EHPA, a ratio of organic/aqueous $=2$ is adequate to achieve a manganese recovery of $95 \%$ in five extraction stages.

To obtain an efficient solvent extraction, the $\mathrm{pH}$ of the leached liquor should be adjusted between 8 and 8.5, although it is suggested a value closer to 8.5. At $\mathrm{pH}$ above this value, the organic-leached liquor dispersion becomes unstable affecting the extraction. Apparently this is because at $\mathrm{pH}$ higher than 8.5 the $\mathrm{Mn}(\mathrm{II})$ is likely to form $\mathrm{Mn}(\mathrm{OH})_{2}$.

The removal of Fe impurities from the leaching solution was conducted by alkaline precipitation and filtering of the $\mathrm{Fe}(\mathrm{OH})_{2}$. This cleaning stage does not increase significantly the operating costs because increasing the $\mathrm{pH}$ is the first step before the manganese solvent extraction.

\section{Acknowledgements}

The authors are grateful to CONACYT (Mexico) and to Huajicari S.A. de C.V. for the scholarship and financing

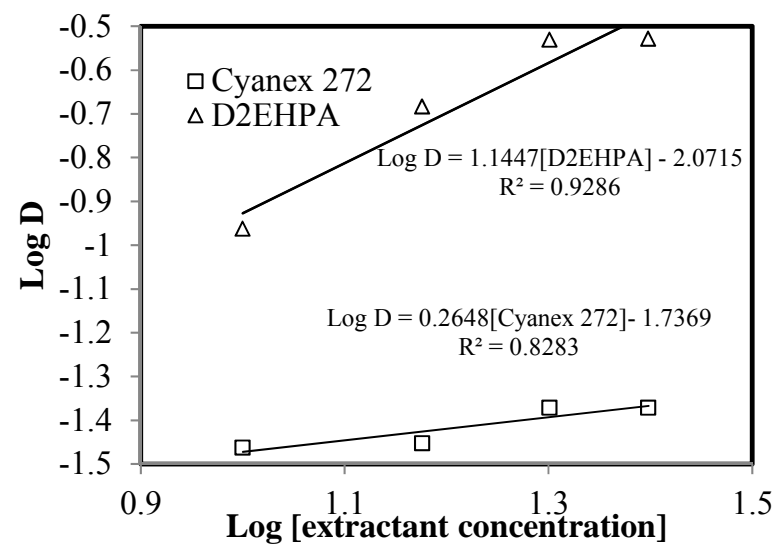

Figure 7. Effect of extractant concentration on the distribution coefficient (D2EHPA and Cyanex 272). $\mathrm{pH}=8$ - 8.5, $25^{\circ} \mathrm{C}, \mathrm{O} / \mathrm{A}=2$, five extraction stages and $1 \mathrm{~min}$ of mixing each stage. 
received.

\section{REFERENCES}

[1] J. B. Calvert, "Chromium and Manganese," 2005. http://www.du.edu/ jcalvert/phys/chromang.htm.

[2] W. Zhang, C. Y. Cheng and Y. Pranolo, "Investigation of Methods for Removal and Recovery of Manganese in Hydrometallurgical Processes," Hydrometallurgy, Vol. 101, No. 1-2, 2010, pp. 58-63. doi:10.1016/j.hydromet.2009.11.018

[3] W. Zhang, P. Singh and D. Muir, "Oxidative Precipitation of Manganese with $\mathrm{SO}_{2} / \mathrm{O}_{2}$ and Separation from Cobalt and Nickel," Hydrometallurgy, Vol. 63, No. 2, 2002, pp. 127-135. doi:10.1016/S0304-386X(01)00205-5

[4] N. Mulaudzi and T. Mahlangu, "Oxidative Precipitation of $\mathrm{Mn}(\mathrm{II})$ from Cobalt Leach Solutions Using Dilute $\mathrm{SO}_{2}$ /Air Gas Mixture," The Journal of Southern African Institute of Mining and Metallurgy, Vol. 109, 2009, pp. 375-381.

[5] J. Van Rooyen, S. Archer and M. Fox, "Manganese Removal from Cobalt Solutions with Dilute Sulphur Dioxide Gas Mixtures," The Fourth Southern African Conference on Base Metals. The Southern Africa Institute of Mining and Metallurgy, Swakopmund, 23-25 July 2007, pp. 365376.

[6] M. Mouton, J. Van Deventer and J. Vaarno, "Oxidative Precipitation of $\mathrm{Fe}$ and $\mathrm{Mn}$ by Air $/ \mathrm{SO}_{2}$," The Fourth Southern African Conference on Base Metals. The Southern Africa Institute of Mining and Metallurgy, Swakopmund, 23-25 July 2007, pp 179-191.

[7] V. Menard and G. Demopuolos, "Gas Transfer Kinetics and Redox Potential Considerations in Oxidative Precipitation of Manganese from an Industrial Zinc Sulphate Solution with $\mathrm{SO}_{2} / \mathrm{O}_{2}$," Hydrometallurgy, Vol. 89, No. 3-4, 2007, pp. 357-368.

doi:10.1016/j.hydromet.2007.03.014

[8] H. Yoshida, H. Nagai and H. Onishi, "Solvent Extraction of Manganese with Thenoyltriflurocetone," Talanta, Vol. 13, No. 1, 1966, pp. 37-42. doi:10.1016/0039-9140(66)80123-6

[9] Y. C. Hoh, W. S. Chuang, B. D. Lee and C. C. Chang, "The Separation of Manganese from Cobalt by D2EHPA," Hydrometallurgy, Vol. 12, No. 3, 1984, pp. 375-386. doi:10.1016/0304-386X(84)90008-2

[10] T. Sato and T. Nakamura, "Solvent Extraction of Divalent
Metals from Sulfuric Acid Solutions by Dialkylphosphoric Acid," Journal of the Mining and Metallurgical Institute of Japan, Vol. 101, No. 1167, 1985, pp. 309-312.

[11] M. A. Hughes and R. K. Biswas, "The Kinetics of Manganese(II) Extraction in the Acidic Sulfate-D2EHPA-nhexane System Using the Rotating Diffusion Cell Technique," Hydrometallurgy, Vol. 32, No. 2, 1993, pp. 209221. doi:10.1016/0304-386X(93)90025-9

[12] C. Y. Cheng, "Purification of Synthetic Laterite Leach Solution by Solvent Extraction Using D2EHPA," Hydrometallurgy, Vol. 56, No. 3, 2000, pp. 369-386. doi:10.1016/S0304-386X(00)00095-5

[13] C. Y. Cheng, M. D. Urbani and M. Houchin, "Manganese Separation by Solvent Extraction in Nickel Laterite Processing," International Laterite Nickel Symposium-TMS 2004 Annual Meeting, Charlotte, 2004, pp. 429-447.

[14] F. Pagnanellia, M. Garavinia, F. Veglio and L. Toroa, "Preliminary Screening of Purification Processes of Liquor Leach Solutions Obtained from Reductive Leaching of Low-Grade Manganese Ores," Hydrometallurgy, Vol. 71, No. 3, 2004, pp. 319-327.

[15] W. Zhang and C. Y. Cheng, "Manganese Metallurgy Review. Part I: Leaching of Ores/Secondary Materials and Recovery of Electrolytic/Chemical Manganese Dioxide," Hydrometallurgy, Vol. 89, No. 3-4, 2007, pp. 137-159. doi:10.1016/j.hydromet.2007.08.010

[16] C. S. Sousa Jr., M. Nascimento, I. O. C. Masson and O. G. C. Cunha, "Equilibrium Study for Manganese Extraction in Sulfate Media with D2EHPA in Isoparaffin (17/21)," Hydrometallurgy, Vol. 103, No. 1-4, 2010, pp. 114-117.

[17] N. B. Devi, K. C. Nathsarma and V. Chakravortty, "Separation of Divalent Manganese and Cobalt Ions from Sulfate Solutions Using Sodium Salt of D2EHPA, PC 88A and Cyanex 272," Hydrometallurgy, Vol. 54, No. 2-3, 2000, pp. 117-131. doi:10.1016/S0304-386X(99)00054-7

[18] A. L. Salgado, A. M. O. Veloso, D. D. Pereira, G. S. Gontijo, A. Salum and M. B. Mansur, "Recovery of Zinc and Manganese from Spent Alkaline Batteries by LiquidLiquid Extraction with Cyanex 272," Journal of Power Sources, Vol. 115, No. 2, 2003, pp. 367-373. doi:10.1016/S0378-7753(03)00025-9

[19] N. B. Devi and S. Mishra, "Solvent Extraction Equilibrium Study of Manganese(II) with Cyanex 302 in Kerosene," Hydrometallurgy, Vol. 103, No. 1-4, 2010, pp. 118-123. doi:10.1016/j.hydromet.2010.03.007 